\section{Staphylokokkus aureus spielt auch bei der allergischen Rhinitis mit}

\author{
Neue Daten weisen darauf hin, dass nasale Staphylokokken in die \\ Pathogenese der allergischen Rhinitis eingreifen und deren Verlauf \\ verschlimmern.
}

\begin{abstract}
A nders als bei Asthma und atopischer A Dermatitis gibt es für die allergische Rhinitis kaum Arbeiten, die sich mit der möglichen Rolle von Bakterien bei Entstehung und/oder Verlauf der Erkrankung befassen. Japanische HNOÄrzte und Mikrobiologen nahmen sich der Frage an.

Sie untersuchten die Kolonisierung der Nasenhöhle durch Staph. aureus sowie dessen SuperantigenProduktion bei 65 Patienten mit perennialer allergischer Rhinitis sowie bei 45 Nicht-Allergikern.

Dabei zeigte sich, dass Staph. aureus aus der Nase von RhinitisPatienten erheblich häufiger isoliert werden konnte als bei den Kontrollpersonen ( 44 vs. $20 \%$; $\mathrm{p}<0,01$ ). $\mathrm{Zu-}$
\end{abstract}

dem produzierten die gefundenen Stämme von Heuschnupfen-Patienten signifikant mehr Superantigen - Lymphozyten der Rhinitiker reagierten mit einer signifikant höheren Proliferation auf die Bakterienprodukte als bei den Gesunden. Die Blutzellen der Patienten produzierten unter dem Einfluss der Staphylokokken-Toxine zudem signifikant größere Mengen von IL-4 und IL-5 als diejenigen der Personen mit gesunder Nase. Dagegen löste der Stimulus bei ihnen einen eindeutig geringeren Synthese-Schub für IFNgamma aus.

In Analogie zur Situation bei der atopischen Dermatitis scheinen also Staphylokokken-Superantigene die Synthese eines TH2-spezifischen Zytokin- musters anzuregen. Dadurch wird die lokale Entzündung weiter angeheizt und die Symptomatik unterhalten.

Tatsächlich hatten S.aureus-positive Patienten gegenüber Rhinitikern, die keine bakterielle Besiedlung aufwiesen, einen signifikant höheren Symptomenscore.

\section{Fazit}

Allergisch entzündete Nasenschleimhäute sowie vermehrter Hand-NaseKontakt scheinen die bakterielle Kolonisierung der Nasenhöhle zu begünstigen. Einmal angesiedelte Staphylokokken greifen offenbar aktiv in die Rhinitis-Pathogenese ein und kurbeln die Entzündungsprozesse an. Ob Betroffenen eine antimikrobielle Behandlung hilft, müssen weitere Studien klären.

wpa

\section{Shiomori T et al.}

Relationship of nasal carriage of Staphylococcus aureus to pathogenesis of perennial allergic rhinitis. J Allergy Clin Immunol 2000; 105: 449-54.

\title{
Invasive und allergische fungale Sinusitis
}

\section{Der Fall einer chronischen Sinusitis, die als invasiver Weichteiltumor imponierte, zeigt die mögliche Reichweite der allergischen Immunreaktion.}

$\mathrm{D}$ ie Schweizer Medizinische Wochenschrift berichtet über den Fall eines 28-jährigen Patienten, der

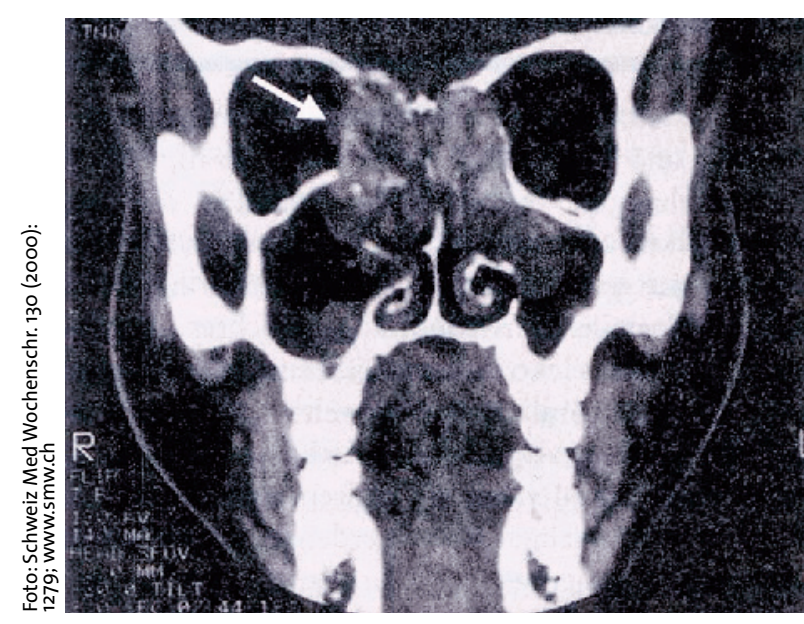

sich mit den Symptomen einer exazerbierenden chronischen Sinusitis in einer Klinik vorstellte. Er klagte über eine Abnahme des Geschmacks- und Geruchssinns sowie rechtsseitiges Nasenbluten beim Schneuzen. Bei der Inspektion fiel eine gerötete Nasenschleimhaut auf, die mit Blut und gelblichen Krusten bedeckt war. Im Differenzialblutbild zeigte sich mit 9\% Anteil eine Eosinophilie.
Das CCT (s. Abb.) ergab den Befund einer Pansinusitis, zusätzlich eines die Orbitawand erodierenden und in die rechte Augenhöhle einbrechenden Weichteiltumors des rechten Sinus maxillaris. Im Resektionspräparat fanden sich Schleimhaut mit vermehrt Eosinophilen sowie Knochennekrosen und -umbauvorgänge. Die Silberimprägnation zeigte hyphale Anteile. In der angelegten Pilzkultur wuchs Curvularia lunata. Der Haut-PrickTest und ein RAST waren für diesen Pilz positiv, Immunglobulin $\mathrm{E}$ und ECP im Serum erhöht. Die Befunde ergaben die Diagnose einer allergischen fungalen Sinusitis.

$t p$

\section{Karcic AA, Karcic E.}

Invasive allergic fungal sinusitis. Schweiz Med Wochenschr 2000; 130: 1279 . 